\title{
Time to Relapse of Severe Acute Malnutrition and Associated Factors Among Under Five Children in Hadiya Zone, Southern Ethiopia.
}

\section{ABERA LAMBEBO TEMAMO ( $\sim$ lambebo70@gmail.com )}

Debre Berhan university https://orcid.org/0000-0002-1580-0364

\section{Deselegn Temiru}

Jimma University College of Public Health and Medical Sciences

\section{Tefera Belachew}

Jimma University College of Public Health and Medical Sciences

\section{Research article}

Keywords: Time to relapse, hazard of relapse, SAM, under five children, Ethiopia

Posted Date: April 5th, 2021

DOl: https://doi.org/10.21203/rs.3.rs-358695/v1

License: (a) (i) This work is licensed under a Creative Commons Attribution 4.0 International License. Read Full License 


\section{Abstract}

\section{Background}

In developing countries including Ethiopia, children under five years old are likely to suffer from repeated bouts of severe acute malnutrition as home level drivers are not mostly improved although the child is discharged after clinical and anthropometric cure. There is lack of study that documented time to relapse of severe acute malnutrition and its determinants.

\section{Objective}

To identify time of relapse and its determinants among children discharged after undergoing treatment for SAM in health facilities of Hadiya Zone, South, Ethiopia

\section{Methods}

An institution based retrospective cohort study was carried out in Hadiya Zone, of Southern Ethiopia among under-five children admitted to health posts for treatment of SAM in the past five years spanning from 2014/2015 to 2019/2020 and discharged after cure. Both first admission data and relapse data were abstracted from the records of the SAM children from Aguste 1-30/2020 Using a data collection format. Data were coded and edited manually, then doubly entered into Epi-Data statistical software version 3.1 and then exported to SPSS for windows version 26. After checking all the assumptions, multivariable Cox Proportional Hazards model was fitted to isolate independent determinants of time to cure. All tests were two sided and $P$ values $<0.05$ were used to declare statistical significance.

Results

The mean $( \pm S D)$ time for relapse of severe acute malnutrition among under five children was $22( \pm 9.9)$ weeks from discharge to relapse time.

On multivariable Cox Proportional Hazards model, after adjusting for background variables the hazard of relapse for severe acute malnutrition was significantly higher for children who had edema during admission with (AHR $=2.02,95 \%, \mathrm{Cl}: 1.17-3.50)$, were in the age group of 6-11 months (AHR $=5.2,95 \%$, Cl:1.95-13.87), had discharge MUAC for the first admission not cured (AHR $=12,95 \%$, Cl: $7.90-19.52)$

\section{Conclusion}

The finding showed that children discharged from Severe acute malnutrition are likely to have relapse in three weeks' time given the prevailing situation of the home environment. Having edema during admission, younger age and not being cured by MUAC at discharge were independent determinants of relapse. The results imply that the need for reviewing follow-up system after discharge and working on the caring practices through behavior change communication to improve the home environment. There also a need for revising the discharge criteria for edematous children rather than basing only on weight change. 


\section{Introduction}

Malnutrition is a significant global public health burden with greater concern among children under five years in Sub-Saharan Africa (1).Nearly half of all deaths in children under 5 are attributable to undernutrition that puts children at greater risk of dying from common infections, increases the frequency and severity of such infections, and delays recovery(2).

In Ethiopia, over 25,000 children with severe acute malnutrition are admitted every month to and the survivors are more likely to perform poorly in school and, once grown up, girls are more likely to suffer from complications during childbirth(3). Severe acute malnutrition (SAM) is a life-threatening condition among the children with children with SAM being nine(4) to 11 times more likely to die than a non-malnourished child(5).

Early identification of severe acute malnutrition is important for initiating treatment and minimizing the risk of complications which can be done in both community and health-care settings using appropriate indicators(6). It can also be prevented by specific interventions on promoting exclusive breastfeeding, vaccination, and timely health care seeking behaviors would definitely improve the outcomes(7).

Malnutrition has many unpleasant results on child health during illness and after discharge. Many children younger than 5 years in developing countries are exposed to multiple risks, including poverty, malnutrition, poor health, and unstimulating home environments, which detrimentally affect their cognitive, motor, and social emotional development(8) and lead to repeated bouts of severe acute malnutrition. Nearly half of all deaths in children under five children are attributable to undernutrition, which puts them at greater risk of dying from common infections, increases the frequency and severity of such infections, and delays recovery(9).

On another hand, relapse after treatment is another challenge for SAM cases reported to be happening at 4 months or 16 weeks post-discharge (10). Close follow-up of children with SAM following discharge is crucial for successful management as complications including relapse and mortality can happen during this period. Weekly follow-up for at least two months is recommended, as these patients have a tendency to relapse. A quarter of these children fail to follow up in six months due to migration, social, political and logistic reasons(11).

However, in Ethiopia there is luck of study that address time to relapse among children with SAM. This study sets out to document time to relapse among children with SAM. This study is of paramount importance in generating evidence for focusing on post discharge status of SAM children.

\section{Methods}

\section{Study area and design}

An institution based retrospective cohort study was conducted among a cohort of children admitted and treated for SAM from 2014/2015-August 30/2020 among 20 selected health posts in Hadiya zone, SNNPR, 
According to the May 24, 2004 World Bank memorandum, $6 \%$ of the inhabitants of Hadiya have access to electricity, this zone has a road density of 104.1 kilometers per 1000 square kilometers compared to the national average of 30 kilometers),(12) the average rural household has 0.6 hectare of land compared to the national average of 1.01 hectare(13) the equivalent of 0.6 heads of livestock. A fifth (22.8\%) of the population has non-farm related jobs, compared to the national average of $25 \%$ and a regional average of $32 \%$. A total of $74 \%$ of all eligible children are enrolled in primary school, and $21 \%$ in secondary schools and $43 \%$ of the zone is exposed to malaria and the memorandum gave this zone a drought risk (14). This zone is characterized by a predominant commitment to agricultural activities, especially the enset-growing, which is often combined with grain including, barley and maize, as well as the breeding of domestic animals(15).

In Hadiya Zone, there were 280 Health Posts (HPs), 60 rural Health Centers, one University teaching Hospital and 3 primary level Hospitals. Hadiya zone is divided into 11 districts for administrative purposes. The vast majority of the population were Hadiya in ethnic group and they earn their living through rain fed agriculture and it has 12 woradas and 2 administrates towns. The woredas were; East Bedewacho, Siraro Bedewacho, West Bedewacho and Shone town administration separated from the rest of the zone by Kembeta Tambaro and the administrative center of Hadiya is Hosanna(16). Of which this was study conducted in two woradas and one town administration among 20 health posts with highest number of cases East Bedewacho (Tikere kokere,Tikare Anbesa,Mahal,Jariso,Amburse Anjulo,2nd Chafa,Eddo,Lenda,Jerso Kutube and Bente Wosen).

Siraro Bedewacho (Abuka,Langano,Dongaro Bonkoya,Wera Bonkoya,sheriko Gafarso,Kumudo,Beshilo,Mahal Korga and Woldia)and Shone Town administration(Wera Gere and Shone town ). The health posts were selected based on number of SAM cases.

\section{Population}

All records of under-five children who were admitted to the health posts of Hadiya Zone,in three woradas from November, 2014/2015-August 30/2020 were the source population. A total of 900 child records were eligible from which 760 were selected by simple random sampling methods using the ENA for SMART software. All records of under-five children with SAM admitted to 20 health post were included, but children with incomplete records, unknown admission dates and unknown discharge dates were excluded.

\section{Sample size determination and sampling procedure}

Sample size was determined from a study conducted in North Gondar zone, Northwest Ethiopia (17). Then, it is calculated by medcalc@ version 119.1.1.3 survival analysis (logranktest) at http://www.medcal.org (18). And diarrhea on admission as the main exposure cured of 51 , censored of 17 , outcome of $75 \%$, AHR of 0.81 and Log rank of 19 total event needed was 484 . As we we selected zones to woradas and from worada to Kebeles, a design effect of 1.5 was considered giving a final sample size of 726 . Finally, the 
records were collected from the card room based on the MRN of the selected participants and the data were collected from these records.

\section{Data collection procedure}

A data extraction tool was prepared from the national treatment protocol for the management of SAM (3), SAM registration booklet, health management information system (HMIS) register. The data extraction format used consisted of socio-demographic data (age, sex) and anthropometric measurements (height, weight, MUAC, edema). Four data collectors (MPH) and one supervisor was recruited based on their experience in data collection. Data collectors received a one-day training on the Extraction tool and were deployed to collect data once the principal investigator was convinced about their competency. The primary investigator of the study and the supervisors critically followed the data collection process to minimize missing information and inconsistencies.

\section{Operational definition}

Relapse rate/repeated episodes; The proportion of children who re-enrolled after they recovered and discharged(19).

Wasting is defined; as low weight-for-height. It often indicates recent and severe weight loss, although it can also persist for a long time(20).

Severe acute malnutrition: It is diagnosed by weight for- height below -3 SD of the WHO standards, by a MUAC $<11.5 \mathrm{~cm}$ and by Clinical sign like bilateral edema (21-23).

Kwashiorkor or edematous malnutrition; is also form of severe under nutrition, the child's muscles were wasted, but wasting may not be apparent due to generalized edema or swelling from excess fluid in the tissues $(21,24)$.

Criteria for discharging children from treatment; weight-for-height/length is $\geq-2$ Z-scores and they have had no oedema for at least 2 weeks, or mid-upper-arm circumference is $\geq 125 \mathrm{~mm}$ and they had no oedema for at least 2 weeks(25).

\section{Data processing and analysis}

Data were coded, entered into Ep-data software version 4.2 and exported to SPSS for windows version 25 software for analysis. The presence of missing values, possible outliers, and multicollinearity were checked through exploratory analysis.

Both bi-variate and multivariable Cox regression analyses were performed. Kaplan Meier hazard curve with the log-rank test was fitted to identify the presence of a difference in recovery rate among the categorical variables. Mantel-Cox and Generalized Wilcoxon test of equality of survival distributions is significant and one minus survival function line is also parallel for those candidate variables of multivariable Cox regression (Fig1 and Fig2). 
For the different levels, under-five children with SAM were followed in weeks from admission to the occurrence of the event (relapse). Person-time was calculated and the incidence was determined. In this study, person-time was reported in child-week. Child-week are total follow up times of each child from admission to the occurrence of the events (relapse or censored)

Those variables with $p \leq 0.25$ in the bi-variable Cox-regression were selected for the multivariable Coxregression analysis. All statistical tests were considered significant at $95 \%$ confidence interval the final significant value is determined at p-values of 0.05 .

Ethical Considerations: Before starting the data collection process, ethical clearance was given secured by Jimma University Health Research Ethics Review Committee (IHRERC). An official letter was written from Jimma University to the Hadiya Zonal Health Office.

Informed written consent was obtained from all health extension workers of selected health posts and woreda health office, confidentiality of the study documents was' information was also ensured according to the Helsinki declaration of ethical code for human subjects.

\section{Results}

\section{Sociodemographic and Anthropometric Characteristics}

In this study, 726 SAM cases seen from registration book for severe acute malnutrition among 20 health posts. From the total admission $640(88.2 \%)$ were new admissions and $86(11.8 \%)$ were relapsed or readmitted with severe acute malnutrition in the last five years and of the total $51 \%$ were females, $24.2 \%$ were in the age of 6-11 months followed by those in the age group of $12-23$ months $(20.2 \%)$.

During the first admission, 33.3\% had edema and the mean weight of children during admission $7.94(( \pm 2.36) \mathrm{kg}$. Similarly, the mean $( \pm S D)$ MUAC of children during admission was $10.60( \pm 0.76) \mathrm{cm}$.

\section{Treatment out comes}

The outcome of SAM treatment for the first admission was majority of children cured for SAM during first admission, $91.9 \%$ cured and followed by those who died (2.8\%). 11(1.5\%),6(0.8\%) and 16(2.2\%) defaulter, unknown status or not recorded, non-response during treatment and transfer out from the program and mean $( \pm S D)$ time for recovery from severe acute malnutrition is $10( \pm 3.3)$ weeks for the first admission. The mean discharge weight was $11.15( \pm 2.1) \mathrm{Kg}$ and mean discharge MUAC was $11.57( \pm 0.81$ ? $) \mathrm{cm}$, when we see the admission condition there were $640(88.2 \%)$ at (95\%, Cl: 85.8-90.2) new admission and $86(11.8 \%)$ at (95\%, Cl:9.8-14.2) relapsed cases for severe acute malnutrition (Table;1)

\section{Time to relapse of SAM}

From the total cases seen $11.8 \%$ had relapse and got readmitted with severe acute malnutrition in last five years. The mean time for relapse of severe acute malnutrition was 22( \pm 9.9$)$ weeks at from discharge of the first admission with minimum and maximum time for relapse was 9 and 67 weeks, respectively. 
There was variation the mean time to relapse by different variables. The mean time of relapse was 21( \pm 8.6$)$ weeks for male children and 24( \pm 11.1$)$ weeks for female children. Likewise, the mean relapse time among edematous children was $22( \pm 11.77)$ weeks. The mean relapse time was shorter for, children 48-60 months $15( \pm 3.52)$, while it was longer for children aged $24-35$ months $21( \pm 8.4)$. (Tabel2)

\section{Determinants of time to relapse}

In Cox Proportional Hazards Model, after adjusting for background variables, children in the younger age (6-11 months) had 5.2 times increased hazard of relapse (AOR=5.2, 95\%, Cl:1.95-13.87) compared to age group of 48-60 months. Similarly, having edema on the first admission increased the hazard of relapse twice (AOR=2.02, (95\%, Cl: 1.17-3.50) compared to non-edematous children. The hazard of relapse was 12 times higher among children who had an outcome of not cured on the first treatment (AOR=12.42, 95\%, Cl: 7.90-19.52) compared to cured ones.

\section{Discussion}

We found out that the mean $( \pm S D)$ time for relapse of severe acute malnutrition among under five children was 22( \pm 9.9$)$ weeks, which is a long relapse time compared to in the report from Nigeria (26). This may be due to differences in study design as study conducted in Nigeria was prospective cohort conducted for only six months, while this study is captured data over five years in addition to being a retrospective cohort which may result in a different result.

In this study, the frequency of relapse was $11.8 \%$ for severe acute malnutrition, which is similar to the report of a study in Burkina Faso (27). This may show that the communalities of the problem and lack of other similar studies for comparison and post discharge status of children with severe acute malnutrition.

On Multivariable analyses, variables that were independent determinants of the hazard of relapse of severe acute malnutrition were: age, having edema on the first admission and not being cured on the first discharge.

Children in the age group of 6-11 months had 5.2 times higher hazards of relapse compared with those in the age of 48-60-months. This study showed that as the age of the child increased the hazard of time to relapse was higher among the age of 6-24 month and finding from this study is in line with other crosssectional study conducted in Ethiopia Afar region(28). This may be at this age children were mostly dependent on maternal source of energy and physiological it includes the age highest demand in energy $\mathrm{kg} /$ day and it also may be the chance of readmission for SAM at this age is high because as we know that screening and admission for malnutrition is mainly limited for the age below 59 months.

Another variable that was significant determinant of the hazard of time relapse was having edema on the first admission. Having edema on the first admission increased the hazard relapse twice compared to nonedematous children. This may be related to early discharge from the program as weight is discharge criteria for SAM cases at health post. Children with edema may have false weight as remnant of nutritional edema. As nutritional oedema affects the function of the glycocalyx are dependent upon sulphated 
proteoglycans and other glycosaminoglycans and fundamentally related to a defect in Sulphur metabolism which can explain all the clinical features of the condition, including the formation of oedema individual may have false weight that related to prior edema (29).

Similarly, children who were not cured during discharge from the first admission had more than 12 times higher hazard of relapse compared to cured ones. This finding is similar with the report of a study conducted in Ethiopia (30). This may be due to the fact that treatment discontinuation like defaulting may increase the risk of readmission as children are not fully treated for the metabolic and nutritional derangements that occurred with severe acute malnutrition.

The results have practical implications for the management of children with SAM. The fact that SAM children with edema and those who were not cured during discharge of the first admission had high hazard of relapse calls for reconsideration of the SAM management protocol and the discharge criteria. It also implies the need for strict monitoring of edema before discharge and follow up of SAM cases to avoid defaulters and partially treated cases through strong awareness creation and counseling of mothers/care givers.

In this study as much as possible we have tried to cover 20 health posts to minimize sampling error. As there is no prior study on time for relapse this study will give new insight for researchers and program planners. As this study is retrospective cohort study, we acknowledge the limitation of not being able to assess multiple determinants, which should be addressed in future study using a prospective cohort design.

\section{Conclusion}

The finding showed that children discharged from Severe acute malnutrition are likely to have relapse in three weeks' time given the prevailing situation of the home environment. Having edema during admission, younger age and not being cured by MUAC at discharge were independent determinants of relapse. The results imply that the need for reviewing follow-up system after discharge and working on the caring practices through behavior change communication to improve the home environment. There also a need for revising the discharge criteria for edematous children rather than basing only on weight change.

\section{Declarations}

Ethics approval and consent to participate; Before starting the data collection process, ethical clearance was given secured by Jimma University Health Research Ethics Review Committee (IHRERC). An official letter was written from Jimma University to the Hadiya Zonal Health Office

Consent for publication; All authors in this work agreed to publish on this journal.

\section{Availability of data and material; yes}

Competing interests; No competing interest 
Funding; no funding organization

\section{Authors' contributions;}

AL; Conceptualization, Data curation, Formal analysis, Investigation, Methodology, Project administration, Resources, Software, Visualization, Writing and original draft.

DT; Conceptualization, Data curation, Formal analysis, Writing and review \& editing.

TB; Conceptualization, Data curation, Formal analysis, Methodology, Resources, Software, Software, Supervision, review \& editing.

Acknowledgements; I want acknowledge my data collectors Morkete Gata and Yordanos Mezemir for their commitment for valuable data extraction and at last but not the least I want to thank my mother Lero Biramo for her advice on my nonacademic work that can have effect on my academic performance.

\section{References}

1. Obasohan PE, Walters SJ, Jacques R, Khatab K. Risk Factors Associated with Malnutrition among Children Under-Five Years in Sub-Saharan African Countries: A Scoping Review. International journal of environmental research and public health. 2020;17(23).

2. UNICEF. 2020.

3. Lanyero B, Teka G, Negash TZ. 2019. [February 20,2021]. Available from: https://www.afro.who.int/news/ethiopia-sets-new-standards-management.

4. Pravana NK, Piryani S, Chaurasiya SP, Kawan R, Thapa RK, Shrestha S. Determinants of severe acute malnutrition among children under 5 years of age in Nepal: a community-based case-control study. 2017;7(8):e017084.

5. AAH. 2019. Available from: https://www.actionagainsthunger.org/research/sam-relapse.

6. WHO. 2019. [February 24/2021]. Available from: https://www.who.int/elena/titles/full_recommendations/sam_management.

7. Sand A, Kumar R, Shaikh BT, Somrongthong R, Hafeez A, Rai D. Determinants of severe acute malnutrition among children under five years in a rural remote setting: A hospital based study from district Tharparkar-Sindh, Pakistan. Pakistan journal of medical sciences. 2018;34(2):260-5.

8. Grantham, Cheung, Cueto, Glewwe, Richter, Strupp. Developmental potential in the fi rst 5 years for children in developing countries. Lancet 2007;369:60-70.

9. UNICEF. 2020. [March 2/2021]. Available from: https://data.unicef.org/topic/nutrition/malnutrition/.

10. Lelijveld N, Musyoki E, Adongo SW, Mayberry A, Wells JC, Opondo C, et al. Relapse and post-discharge body composition of children treated for acute malnutrition using a simplified, combined protocol: $\mathrm{A}$ nested cohort from the ComPAS RCT. PloS one. 2021;16(2):e0245477.

11. UNICEF. 2020. [March 2/2021]. Available from: https://www.unicef-irc.org/article/959-challenges-inthe-management-of-malnut. 
12. World Bank. 2003. Available from: https://openknowledge.worldbank.org/handle/10986/5985.

13. al. KDe. Comparative national and regional figures comes from the World Bank publication, "Tenure Security and Land Related Investment", WP-2991 Archived at the Wayback Machine. . 2007.

14. World Bank. 2006. Available from:

http://siteresources.worldbank.org/INTETHIOPIA/Resources/PREM/FourEthiopiasrev6.7.5.May24.pdf.

15. VALENTINA PEVERI. NUTRITION AND IDENTITY IN HADIYA ZONE (SOUTH-CENTRAL ETHIOPIA). University of Bologna, Department of Historical, Anthropological and Geographical Sciences,1997.

16. Wikipedia. Ethiopia. the free encyclopedia2019.

17. Mamo WN, Derso T, Gelaye KA, Akalu TY. Time to recovery and determinants of severe acute malnutrition among 6-59 months children treated at outpatient therapeutic programme in North Gondar zone, Northwest Ethiopia: a prospective follow up study. Italian Journal of Pediatrics. 2019;45(136).

18. MedCalc Statistical Software version 19.1.3. MedCalc Software. In: Ostend B, editor. 2019.

19. Akparibo R, CK Lee A, Booth A, Harris J, Woods HB, Blank L. Relationships between recovery and relapse, and default and repeated episodes of default in the management of acute malnutrition in children in humanitarian emergencies. 2015.

20. WHO. Organization. Wh, editor: WHO. 2020. Available from: https://www.who.int/news-room/factsheets/detail/malnutritio.

21. UNICEF. UNICEF Strategic Plan 2014-2017 contact:Director, Division of Policy and Strategy. In: Plaza U, editor. New York, NY 100172014.

22. UNICEF. UNICEF Data: Monitoring the situation of children and women. 2019.

23. WHO, UNICEF. WHO child growth standards and the identification of severe acute malnutrition in infants and children. 20 Avenue Appia, 1211 Geneva 27, Switzerland; 2009.

24. WHO. WHO child growth standards and the identification of severe acute malnutrition in infants and children. 2009.

25. WHO WHO. Guideline: Updates on the management of severe acute malnutrition in infants and children. WHO Library Cataloguing-in-Publication Data. 20 Avenue Appia, 1211 Geneva 27, Switzerland (tel.: +41 22 7913264; fax: +41 22791 4857; e-mail: bookorders@who.int). WHO Press; 2013.

26. Adegoke O, Arif S, Bahwere P, Harb J, Hug J, Jasper P, et al. Incidence of severe acute malnutrition after treatment: A prospective matched cohort study in Sokoto, Nigeria. Matern Child Nutr. 2021;17(1):e13070.

27. Somasse YE, Dramaix M, Bahwere P, Donnen P. Relapses from acute malnutrition and related factors in a community-based management programme in Burkina Faso. Matern Child Nutr. 2016;12(4):90817.

28. Gebre A, Reddy PS, Mulugeta A, Sedik Y, Kahssay M. Prevalence of Malnutrition and Associated Factors among Under-Five Children in Pastoral Communities of Afar Regional State, Northeast 
Ethiopia: A Community-Based Cross-Sectional Study. Journal of nutrition and metabolism. 2019;2019:9187609.

29. Golden MH. Nutritional and other types of oedema, albumin, complex carbohydrates and the interstitium - a response to Malcolm Coulthard's hypothesis: Oedema in kwashiorkor is caused by hypo-albuminaemia. Paediatrics and international child health. 2015;35(2):90-109.

30. Abate BB, Tilahun BD, Kassie AM, Kassaw MW. Treatment outcome of Severe Acute Malnutrition and associated factors among under-five children in outpatient therapeutics unit in Gubalafto Wereda, North Wollo Zone, Ethiopia, 2019. PloS one. 2020;15(9):e0238231.

\section{Tables}

Table; 1 Profile of admitted children with severe acute malnutrition (SAM) in Sothern Region Hadiya zone Ethiopia. 


\begin{tabular}{|c|c|}
\hline Variable & Frequency (\%) \\
\hline \multicolumn{2}{|l|}{ Sex } \\
\hline Male & $352(48.5)$ \\
\hline female & $374(51.2)$ \\
\hline \multicolumn{2}{|l|}{ Age } \\
\hline 6-11 months & $176(24.2)$ \\
\hline 12-23 months & 147(20.2) \\
\hline 24-35 months & 136(18.7) \\
\hline 36-47 months & 172(23.7) \\
\hline $48-60$ months & $95(13.1)$ \\
\hline \multicolumn{2}{|c|}{ Edema during admission } \\
\hline Yes & 242(33.3) \\
\hline No & 484(66.7) \\
\hline \multicolumn{2}{|l|}{ Outcome } \\
\hline Cured & 667(91.9) \\
\hline Dead & $6(0.8)$ \\
\hline Defaulter & $20(2.8)$ \\
\hline Unknown & $11(1.5)$ \\
\hline Non response & $6(0.8)$ \\
\hline Transfer out & $16(2.2)$ \\
\hline \multicolumn{2}{|c|}{ Type of admission } \\
\hline New & 640(88.2) \\
\hline Relapsed & $86(11.8)$ \\
\hline
\end{tabular}

Table;2 Mean time of relapse among children with severe acute malnutrition (SAM) in Sothern Region Hadiya zone Ethiopia. 


\begin{tabular}{|lll|}
\hline Variable & Mean time of relapse in week & $\mathbf{\pm S D}$ \\
\hline Sex & 21 & \\
Male & 23 & 8.6 \\
Female & & 11.1 \\
$6-11$ & 21 & 21.4 \\
$12-23$ & 25 & 25.2 \\
$24-35$ & 26 & 15 \\
$36-47$ & 21 & 8.3 \\
$48-60$ & 15 & 3.5 \\
Edema during first admission & & \\
Yes & & 11.8 \\
No & 22 & 8.7 \\
\hline Outcome of treatment & 22 & \\
Cured & & 11.8 \\
Not cured & 23 & 7 \\
\hline
\end{tabular}

Table 3. Cox proportional hazards model identifying the determinants of time to relapse among children with severe acute malnutrition (SAM) in Sothern Region Hadiya zone Ethiopia. 


\begin{tabular}{|c|c|c|c|c|}
\hline Variables & $\underline{B}$ & $\underline{\mathbf{P}}$ & $\underline{\mathrm{AHR}}$ & $95.0 \% \mathrm{Cl}$ for $\mathrm{AHR}$ \\
\hline$\underline{\text { Sex }}$ & - & - & - & - \\
\hline Male & $=$ & $=$ & $=$ & $=$ \\
\hline Female & $\underline{-0.32}$ & $\underline{0.16}$ & $\underline{0.72}$ & $\underline{0.46-1.14}$ \\
\hline$\underline{\text { Admission edema }}$ & - & - & - & - \\
\hline$\underline{\text { Yes }}$ & $\underline{0.70}$ & $\underline{0.01}$ & $\underline{2.02}$ & $\underline{1.17-3.50}$ \\
\hline No & $=$ & $=$ & $=$ & $=$ \\
\hline Admission MAC & $\underline{-0.10}$ & $\underline{0.53}$ & $\underline{0.90}$ & $\underline{0.65-1.25}$ \\
\hline Age of the child in month & - & - & - & - \\
\hline$\underline{6-11}$ & - & - & - & - \\
\hline$\underline{12-23}$ & $\underline{1.65}$ & $\underline{0.001}$ & $\underline{5.200}$ & $\underline{1.95-13.87}$ \\
\hline$\underline{24-35}$ & $\underline{0.79}$ & $\underline{0.151}$ & $\underline{2.194}$ & $\underline{0.75-6.41}$ \\
\hline$\underline{36-47}$ & $\underline{0.80}$ & $\underline{0.131}$ & $\underline{2.230}$ & $\underline{0.79-6.31}$ \\
\hline \multirow[t]{2}{*}{$48-60$} & $\underline{0.86}$ & $\underline{0.090}$ & $\underline{2.369}$ & $\underline{0.87-6.42}$ \\
\hline & $=$ & $=$ & $=$ & $=$ \\
\hline Outcome during discharge & - & - & - & - \\
\hline$\underline{\text { Cured }}$ & - & - & - & - \\
\hline \multirow[t]{3}{*}{$\underline{\text { Not cured }}$} & - & - & - & - \\
\hline & $=$ & $=$ & - & $=$ \\
\hline & 2.519 & $\underline{0.001}$ & 12.42 & 7.90-19.52 \\
\hline
\end{tabular}

Figures 


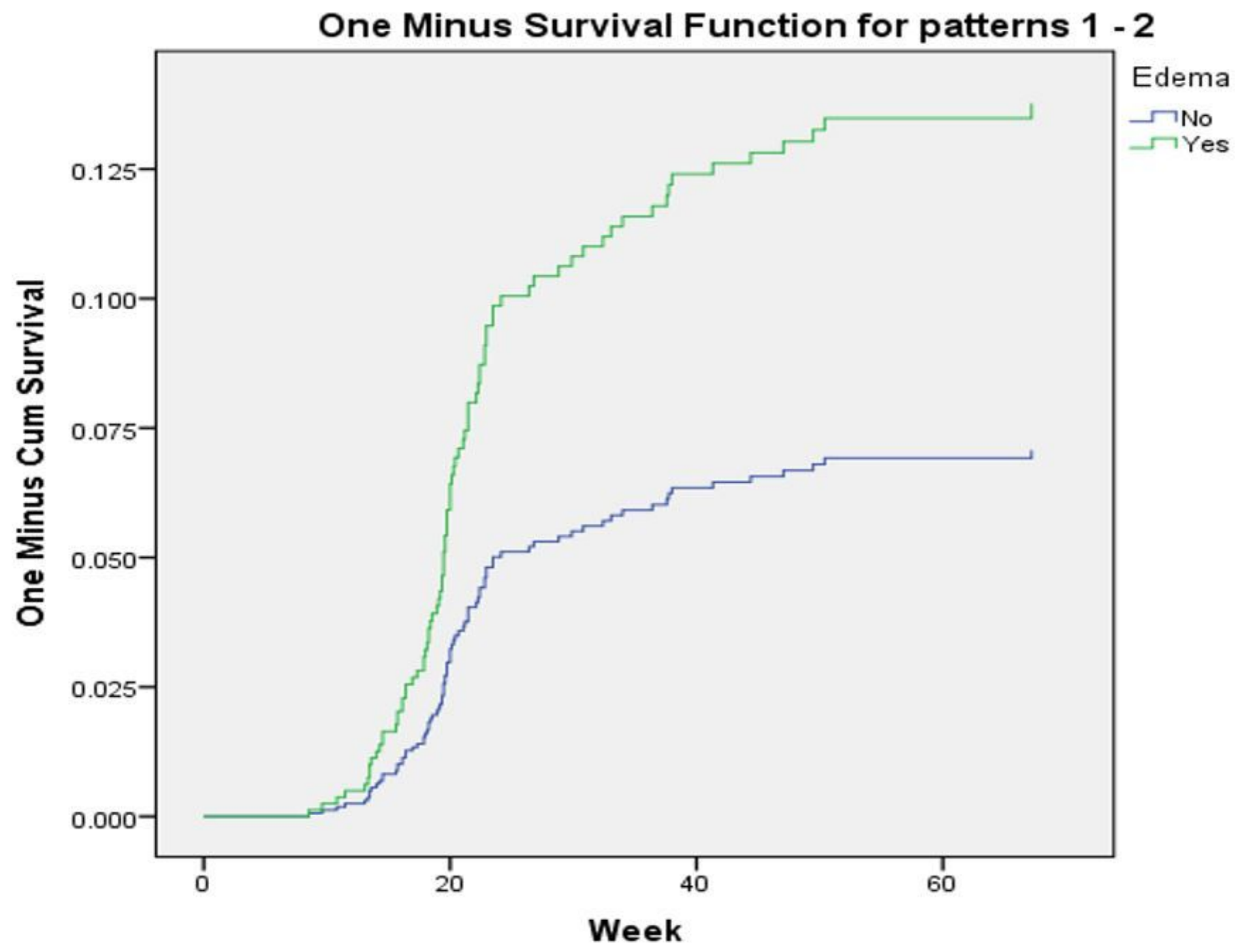

Figure 1

one minus survival function test for edematous children in Hadiya zone Southern Ethiopia 


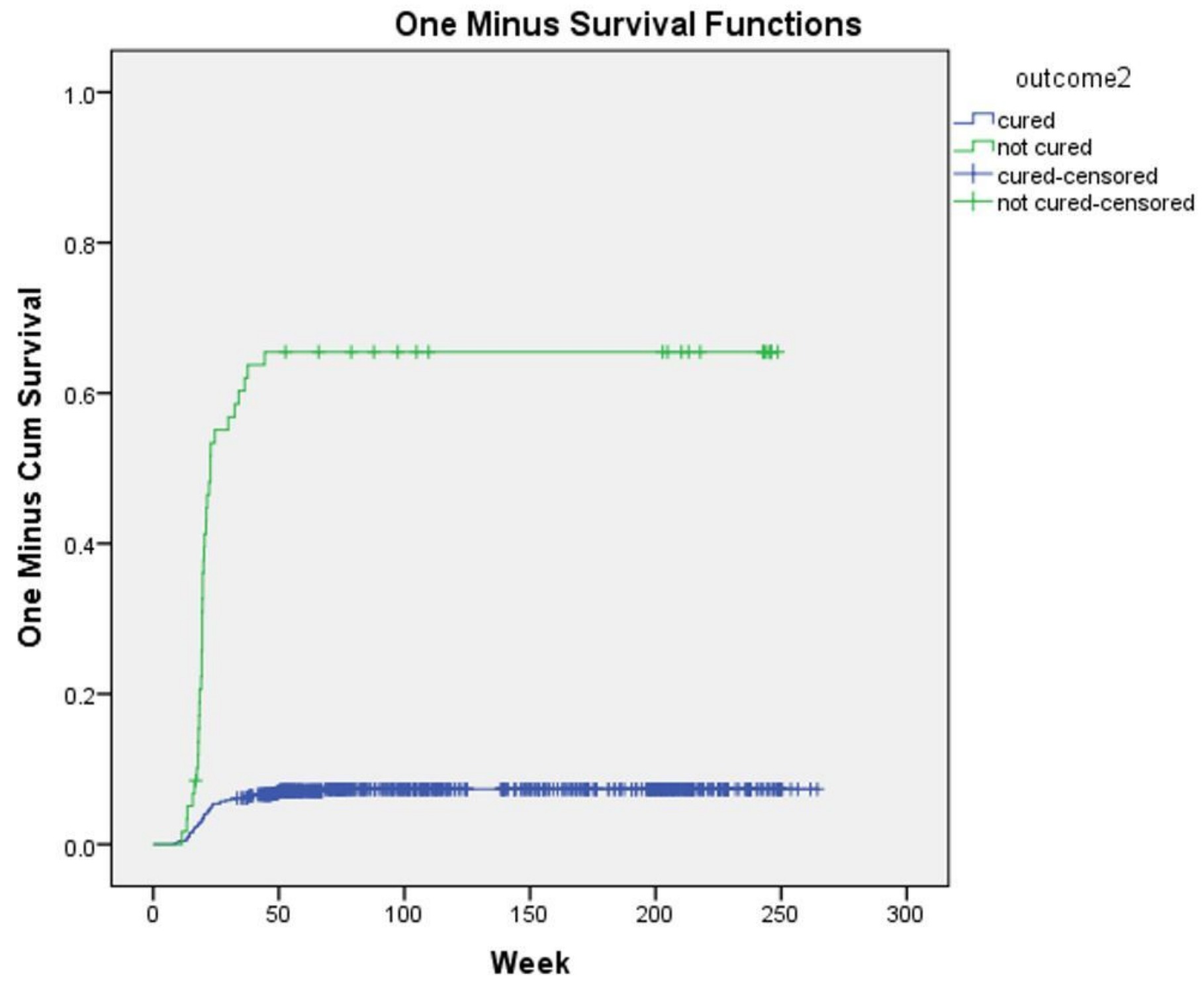

Figure 2

One minus curve for testing parallel hazards assumption among children in Hadiya zone Southern Ethiopia 